\title{
Contrasting funding and author data for PERC proceedings and PRPER
}

\author{
Rebecca Rosenblatt \\ AAAS Science and Technology Policy Fellow \\ Alexandria, VA 22301 \\ rosenblatt.rebecca@gmail.com
}

This study informs the Physics Education Research (PER) community about patterns in reported funding and authorship data between 2010 and 2019. The study involves a text-based analysis of all contributed PERC and Physical Review PER papers during this time to identify funding sources, author collaborations, and changes over time. PERC and PRPER are both central to publication in the PER community, but are different in terms of project stage and publication prestige. Physical Review articles are in general mature projects, and this is the more prestigious publication venue. PERC proceedings represent the community across a broader set of authors and project stages. Results are also contrasted with the Frontiers in Education proceedings to provide context to these findings. The goal of this work is to provide insight into the community's history and to provide a benchmark for funding and collaboration in PER prior to the Covid-19 pandemic. 


\section{INTRODUCTION}

This study reports on author and funding data from all Physical Review Physics Education Research (PRPER) articles from 2010-2019. This analysis is a follow up to a paper in PERC 2020 that was a similar analysis of the contributed PERC proceedings [1]. These data are also contrasted with results from the Frontiers in Education (FIE) proceedings. The FIE conference is a major international conference focusing on Engineering and Computing Education Research and has many commonalities with Physics Education Research (PER) given the similarities of engineering and physics [2].

This historical publication analysis is useful because it informs on the scope of funding and collaboration of the PER community in PRPER and PERC, identifies grant streams important to the community, and indicates leverage points for using existing partnerships to innovate PER. Also, contrasting PRPER and PERC results to those from FIE offers improved understanding of the importance of these results given the similarities of these two related discipline based education research communities. The overarching goal of this work is to provide insight into the community's history and trajectory so that the community can make informed decisions regarding future research, collaborations, and funding choices.

This research is motivated by the increased recognition, by government funding agencies, for the need to invest in partnerships/collaborations to achieve future-looking goals [3-6]. The PER community is uniquely placed to capitalize on these funding shifts as it sits in the overlaps of education, physics, and many other disciplines. However, understanding the history of funding and coauthor partnerships can be useful in determining how these policies might benefit the community.

Finally, this research is even more significant given the Covid-19 pandemic as it provides a benchmark for future efforts to investigate how the community's collaborations and research outcomes have been effected. The Covid-19 pandemic has put unprecedented strain on higher-education communities. It is hoped that the efforts by the community, to maintain research productivity and student support, will mitigate issues to the extent that nothing can be seen in the publication record. However, it may be of interest to follow these funding and collaboration data through the next few years to see if there is visible impact on funding and research outputs in publications from the PER and FIE communities.

This research seeks to answer the guiding research questions: What is the landscape of funding and collaboration in PER among those who are published in PRPER and the contributed PERC proceedings and how has this changed with time? In addition, the following questions about funding were identified: Since a majority of funding for these papers comes from the U.S. National Science Foundation, what funding streams are represented? Data on institutional collaborations as represented by co-authorship seeks to answer the questions. Do PRPER articles represent more collaborative work as shown by more inter-institutional papers or larger collaborations? Which institutions and authors publish in these two places, and how are these different? Are patterns of collaboration seen in PERC mirrored in those from PRPER?

\section{METHODOLOGY}

To answer these research questions, a text-based analysis was conducted of the PRPER, PERC, and FIE articles from 2010 to 2019 . These articles are publicly available and free [7-9]. They were selected because of the central role PRPER and PERC play in the PER community and the similarities of PER and Engineering Education. This analysis follows a rich history of similar text-based meta-analysis of publications in these two research communities [10-15].

For analyses of funding streams, information about the grant, or grants, that supported each paper's work were scraped using an advanced lexicon search within MAXQDAC. Steps include the following: locating and downloading all digital (.pdf) volumes for the conference proceedings; searching for case sensitive "Acknowledg*" that captures common spellings for the acknowledgments sections; cleaning the data; open coding of acknowledged funding; identifying and extracting all 7-digit award codes from NSF; pulling data from NSF awards search [16]; and cleaning the data to link to NSF directorate, division, and program.

Author collaborations were analyzed by using "DOI" to capture the end of the abstract in PRPER, "Abstract" for FIE, and "Introduction" for PERC and pulling the starting text of each article. Open coding was then used to extract the title, author names, and institutional affiliations. Author and institution names were cleaned to match identical people or institutions as much as possible. However, because of the variety of ways people name themselves or their institutions there are likely some people and institutions who were counted twice.

\section{FUNDING ANALYSIS: CONTRASTING PRPER, PERC, AND FIE ACKNOWLEDGED FUNDING TRENDS}

There were 606 papers published as part of PRPER from 2010-2019. 451 papers (74\%, simple-year-average of $73 \%$ ) acknowledged funding (see Table I). 306 (50\% of papers) acknowledged the U.S. National Science Foundation (NSF) as a funding source with 301 giving the seven-digit number for that funding. Additionally, 92 papers (15\%) acknowledged an international funding body, 84 papers (14\%) acknowledged "local" - institution, department, or teaching center - funding, and 31 papers (5\%) acknowledged funding from another U.S. source such as the Dept. of Ed., HHMI, NASA, NIH, or other.

Of the 451 PRPER papers that acknowledged funding, a majority of papers, 68\% (simple-yearly-average 67\%), acknowledged NSF, 20\% acknowledged international funding (i.e. non-U.S. based funding bodies), $18 \%$ acknowledged local funding, and 7\% other U.S. based funding. Table I presents this acknowledged funding data from PRPER broken down by year and the percentage of funding from each 
TABLE I. Funding Acknowledged in PRPER \& Contributed PERC Papers from 2010-2019

$\%$ of Papers Funded = \# with Funding/ \# of Papers; \% of Funding by NSF = \# with NSF Funding/ \# with Funding; Avg = Arithmetic by Year

\begin{tabular}{|c|c|c|c|c|c|c|c|c|c|c|c|c|}
\hline PRPER Papers from 2010-2019 & 2010 & 2011 & 2012 & 2013 & 2014 & 2015 & 2016 & 2017 & 2018 & 2019 & Avg & Total \\
\hline \# of Papers & 33 & 30 & 45 & 45 & 52 & 55 & 90 & 76 & 81 & 99 & 61 & 606 \\
\hline \# Acknowledging Funding & 25 & 15 & 36 & 26 & 39 & 43 & 64 & 62 & 61 & 80 & 45 & 451 \\
\hline \# Acknowledging NSF Funding & 18 & 8 & 28 & 16 & 20 & 32 & 48 & 43 & 41 & 52 & 31 & 306 \\
\hline$\%$ of Papers Funded & $76 \%$ & $50 \%$ & $80 \%$ & $58 \%$ & $75 \%$ & $78 \%$ & $71 \%$ & $82 \%$ & $75 \%$ & $81 \%$ & $73 \%$ & - \\
\hline$\%$ of Funding by NSF & $72 \%$ & $53 \%$ & $78 \%$ & $62 \%$ & $51 \%$ & $74 \%$ & $75 \%$ & $69 \%$ & $67 \%$ & $65 \%$ & $67 \%$ & - \\
\hline$\%$ of Funding by International Agencies & $16 \%$ & $20 \%$ & $25 \%$ & $19 \%$ & $28 \%$ & $12 \%$ & $19 \%$ & $23 \%$ & $15 \%$ & $25 \%$ & $20 \%$ & - \\
\hline$\%$ of Funding by Local Means & $20 \%$ & $27 \%$ & $3 \%$ & $15 \%$ & $15 \%$ & $19 \%$ & $20 \%$ & $19 \%$ & $18 \%$ & $25 \%$ & $18 \%$ & - \\
\hline PERC Papers from 2010-2019 & 2010 & 2011 & 2012 & 2013 & 2014 & 2015 & 2016 & 2017 & 2018 & 2019 & Avg. & Total \\
\hline \# of Papers & 67 & 72 & 95 & 84 & 70 & 93 & 97 & 115 & 113 & 112 & 92 & 918 \\
\hline \# w/ Funding & 50 & 52 & 62 & 58 & 42 & 66 & 53 & 73 & 81 & 75 & 61 & 612 \\
\hline \# w/ NSF Funding & 35 & 41 & 51 & 46 & 32 & 49 & 45 & 59 & 62 & 61 & 49 & 489 \\
\hline$\%$ of Papers Funded & $74 \%$ & $72 \%$ & $65 \%$ & $69 \%$ & $60 \%$ & $71 \%$ & $54 \%$ & $63 \%$ & $72 \%$ & $67 \%$ & $67 \%$ & - \\
\hline$\%$ of Funding by NSF & $76 \%$ & $83 \%$ & $85 \%$ & $79 \%$ & $76 \%$ & $76 \%$ & $85 \%$ & $81 \%$ & $77 \%$ & $81 \%$ & $80 \%$ & - \\
\hline
\end{tabular}

of the 3 main "sources". (Note: a paper can have multiple funding sources. For example, 19 papers had NSF and local funding, and 9 papers had NSF and international funding.)

For the PERC proceedings from 2010-2019, there were 918 contributed papers. 612, or $67 \%$ of papers, acknowledged funding. 489 papers, or $53 \%$ of papers, acknowledged NSF funding with 481 giving the seven-digit number for that funding. Additionally, $80 \%$ of the papers that acknowledged funding credited NSF as one of the funding sources (see Table I). The PERC community was also funded by: local grants at 69 funding acknowledgments (11\% of the papers that acknowledged funding); international sources, 5\%; and other U.S. sources account for approximately $4 \%$.

For FIE proceedings papers from 2010-2019, there were 4,134 total papers. Only 34\% $(1,412)$ of papers, acknowledged some source of funding and only $18 \%$ (753) of papers acknowledged NSF for funding. Of the papers that acknowledged funding, $53 \%$ credited NSF as one of the funding sources, $30 \%$ credited international funding sources, and $12 \%$ acknowledged local sources for funding. While these three sources are not mutually exclusive, overlaps were rare for this publication. Thus, these three sources of funding account for $96 \%$ of all acknowledged funding [2].

Contrasting these publications, there are a few clear differences in the makeup of these communities and their funding. The PER community as represented by PRPER and PERC publications is less than 1/4 the size of the Engineering and Computer Science Education community (as represented by the FIE proceedings); however, the funding rate to the PER community is significantly higher than that for the FIE community. The average funding rate of the PER community at $73 \%$ (PRPER) and 67\% (PERC) is two times that of the FIE proceedings at $34 \%$. In addition, there was a significant overall decrease in the percentage of papers reporting funding for the FIE proceedings across this 10-year time [2]. While the funding acknowledged in PERC and PRPER increased as the publication numbers increased, so the percentage of papers funded each year remained roughly constant (see Table I).

\section{SOURCES OF ACKNOWLEDGED FUNDING}

The funding rate of $73 \%$ for PRPER and $67 \%$ for PERC makes it clear that the PER community, as a whole, and as represented by publication in PRPER and PERC, has been successful in finding funding. However, it can be useful to know the exact sources of this funding either from a policy perspective in understanding the financial stability of the field or from a researcher perspective in wondering what may be good places to apply for grant money for their work. Table II shows the numbers and percentages for awards by NSF directorate from PRPER, PERC, and FIE acknowledgements.

Education and Human Resources accounts for $78 \%$ of NSF funding acknowledged in PRPER (175 unique awards). Within EHR, the division of undergraduate education accounts for $72 \%$ (127) of these awards. The programs are: 43 awards from IUSE/CCLI/TUES, 58 from IUSE \& SSTEM, and 13 from NOYCE. Interestingly no ATE awards were acknowledged suggesting that PRPER work might have relatively little collaboration with 2-year programs. Other sources of awards from EHR were DRL with 33 awards (14 REAL, 8 DRK12, 5 AISL), DGE with 9 awards (5 GRFP, 3 ECR, and 1 AGEP), and HRD with 6 awards (5 ECR and 1 ADVANCE). (Note: if a division or program abbreviation is unfamiliar a google search of NSF and the acronym will provide the relevant webpage. Table II reports the directorates.)

MPS only accounted for 14\% (32) of these NSF awards. 23 MPS awards were from Physics (with 9 of these awards from the Integrative Activities program), 5 awards were from the Division of Materials Research and 4 from Astronomy. 
TABLE II. NSF directorates of the acknowledged grants in PRPER, PERC, and FIE papers from 2010-2019

\begin{tabular}{l|cc|cc|cc} 
& \multicolumn{2}{|c|}{ PRPER } & \multicolumn{2}{c|}{ PERC } & \multicolumn{2}{c}{ FIE } \\
Directorate & Grants & Percent & Grants & Percent & Grants & Percent \\
EHR & 175 & $78 \%$ & 205 & $80 \%$ & 331 & $54 \%$ \\
MPS & 32 & $14 \%$ & 31 & $12 \%$ & 9 & $2 \%$ \\
ENG & 1 & $0 \%$ & 4 & $2 \%$ & 178 & $29 \%$ \\
CISE & 3 & $1 \%$ & 3 & $1 \%$ & 68 & $11 \%$ \\
Other & 1 & $0 \%$ & 2 & $1 \%$ & 14 & $2 \%$ \\
N/A & 12 & $5 \%$ & 10 & $4 \%$ & 19 & $3 \%$ \\
\hline Total & 224 & $100 \%$ & 255 & $100 \%$ & 614 & $100 \%$
\end{tabular}

Education and Human Resources (EHR); Mathematical and

Physical Sciences (MPS); Engineering (ENG); Computer Science

(CISE); (N/A) No such grant \# exists in the awards search.

These are the main funding programs as reported from the awards search. However, these are not necessarily the best funding programs to apply to. NSF programs change with time; funding announcements are what a PI should use to determine whether their research idea fits within a program. Additionally, these data are awards only and do not mean that these programs have a higher likelihood of funding.

Interestingly, PRPER, which is the more prestigious publication venue, has a very similar funding rate to PERC and almost identical directorate sources. This might be assumed to be because a similar set of authors publish in both places. However, of the 224 unique NSF awards acknowledged in PRPER only 127 (60\%) were also acknowledged in PERC, and in the reverse, 128 of the 255 awards acknowledged in PERC were not in PRPER. So, despite the similarities in the funding landscapes of these two publications there is only a 50 to 60 percent overlap in the actual awards.

\section{COAUTHOR ANALYSIS: CONTRASTING PRPER, PERC, AND FIE AUTHOR TRENDS}

As the PER community moves forward into new and interesting innovations, it is useful to reflect on the partnerships and collaborations between PER researchers and the outcomes of these partnerships. This analysis focuses on the general question: what are the patterns seen in collaboration on PRPER papers from 2010 to 2019 and are these consistent with those seen in PERC? PRPER author data was analyzed for the number of authors who collaborated on papers, whether these collaborations were multi-institutional or single institution, what countries were involved in these collaborations, and which institutions published. These data are contrasted with data from an analysis of author data in PERC from 2010-2019 [1] and FIE data [2] and complements results from a previous study that focused on researcher collaborations rather than institutional collaborations in PRPER, AJP, and PERC from 1980-2010 [14].

There were 606 PRPER articles from 2010-2019 [7]. Only

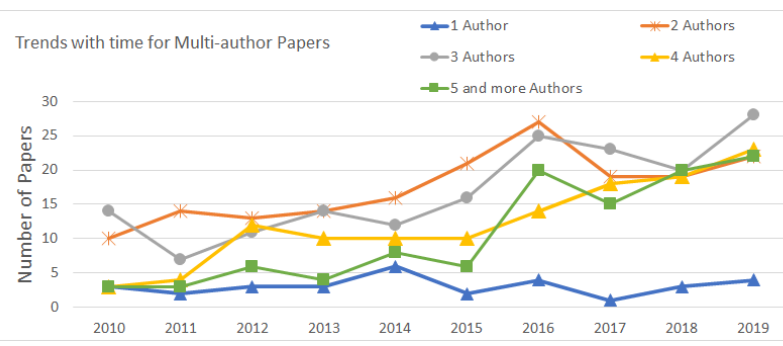

FIG. 1. Trend with time toward more collaborative papers.

31 of these papers, 5\%, were single author and 575, 95\%, were collaborations of multiple authors (See Table III). This is similar to PERC data during this time where 65 of these 918 contributed papers, i.e. $7 \%$, were single author and $93 \%$ were collaborations with multiple authors. This is also similar to FIE data where $13 \%$ of papers were solo. The average number of authors on PRPER, PERC, and FIE papers were all 3.3 authors per paper. In addition, all three publications showed increases in the number of of articles with 4 and more authors across this 10-year time frame with PRPER showing large increases in the number of all collaborative publications between 2015 and 2016, which was sustained through 2019 (see Figure 1). These data indicate that the three publications are very similar in terms of the numbers of authors on a paper. However, the institutional collaborations on PRPER are fairly different than PERC and FIE.

Of the 606 PRPER papers, only $46 \%$ are collaborations where all authors are at the same institution. This is in contrast to PERC data where $63 \%$ of papers had all authors at the same institution and FIE data which had $72 \%$ of papers being single institution [1, 2]. In addition, 25\% (142) of the multiauthor PRPER papers are collaborations where authors were at three or more institutions compared to around $10 \%$ for both PERC and FIE. These data show that at least $15 \%$ more

TABLE III. Coauthorship in PRPER, PERC, and FIE 2010-2019

Note: Cor. is the correlation of papers in each category w/ year.

\begin{tabular}{|c|c|c|c|c|c|c|c|c|c|}
\hline \multirow[b]{2}{*}{ \# Category } & \multicolumn{3}{|c|}{ PRPER } & \multicolumn{3}{|c|}{ PERC } & \multicolumn{3}{|c|}{ FIE } \\
\hline & \# & $\%$ & Cor. & \# & $\%$ & Cor. & \# & $\%$ & Cor. \\
\hline 1 Author & 31 & $5 \%$ & +0.1 & 65 & $7 \%$ & -0.0 & 539 & $13 \%$ & -0.4 \\
\hline 2 Authors & 175 & $29 \%$ & +0.1 & 262 & $29 \%$ & -0.4 & 1063 & $26 \%$ & -0.6 \\
\hline 3 Authors & 170 & $28 \%$ & +0.8 & 257 & $28 \%$ & +0.0 & 977 & $24 \%$ & -0.2 \\
\hline 4 Authors & 123 & $20 \%$ & +0.8 & 197 & $21 \%$ & +0.7 & 692 & $17 \%$ & +0.5 \\
\hline 5+ Authors & 107 & $18 \%$ & +0.9 & 137 & $15 \%$ & +0.8 & 863 & $21 \%$ & +0.6 \\
\hline 1 Place & 276 & $46 \%$ & +0.6 & 582 & $63 \%$ & +0.7 & 2983 & $72 \%$ & -0.2 \\
\hline 2 Places & 187 & $31 \%$ & +0.7 & 232 & $25 \%$ & +0.7 & 774 & $19 \%$ & +0.3 \\
\hline 3 Places & 93 & $15 \%$ & +0.8 & 77 & $8 \%$ & +0.6 & 253 & $6 \%$ & +0.2 \\
\hline 4 Places & 36 & $6 \%$ & +0.5 & 23 & $3 \%$ & +0.8 & 61 & $1 \%$ & +0.3 \\
\hline 5+ Places & 14 & $2 \%$ & +0.4 & 4 & $0 \%$ & +0.4 & 63 & $2 \%$ & +0.2 \\
\hline Total Papers & 606 & - & +0.3 & 918 & - & +0.9 & 4134 & - & +0.0 \\
\hline
\end{tabular}


TABLE IV. Top 20 institutions by \# of PRPER publications

\begin{tabular}{lcr}
\hline \hline Years 2010-2019 & $\begin{array}{c}\text { PRPER } \\
\text { Institution }\end{array}$ & $\begin{array}{r}\text { PERC } \\
\text { of papers }\end{array}$ \\
\hline University of Colorado Boulder & $67(11 \%)$ & $130(14 \%)$ \\
University of Pittsburgh & $36(6 \%)$ & $57(6 \%)$ \\
Florida International University & $34(6 \%)$ & $47(5 \%)$ \\
Ohio State University & $31(5 \%)$ & $26(3 \%)$ \\
Kansas State University & $29(5 \%)$ & $46(5 \%)$ \\
Michigan State University & $28(5 \%)$ & $54(6 \%)$ \\
University of Maryland & $27(4 \%)$ & $35(4 \%)$ \\
University of Maine & $25(4 \%)$ & $24(3 \%)$ \\
Seattle Pacific University & $19(3 \%)$ & $27(3 \%)$ \\
University of Illinois (UIUC) & $19(3 \%)$ & $12(1 \%)$ \\
Western Michigan University & $18(3 \%)$ & $31(3 \%)$ \\
University of Cincinnati & $14(2 \%)$ & $7(1 \%)$ \\
University of Washington & $14(2 \%)$ & $25(3 \%)$ \\
Oregon State University & $13(2 \%)$ & $28(3 \%)$ \\
KU Leuven & $12(2 \%)$ & $1(0 \%)$ \\
Rochester Institute of Technol. & $12(2 \%)$ & $27(3 \%)$ \\
University of British Columbia & $12(2 \%)$ & $7(1 \%)$ \\
University of Zagreb & $11(2 \%)$ & $0(0 \%)$ \\
West Virginia University & $11(2 \%)$ & $3(0 \%)$ \\
Harvard University & $10(2 \%)$ & $4(0 \%)$ \\
\hline Unique Papers Counted Above & $354(58 \%)$ & $514(56 \%)$ \\
\hline Additional institutions & $330+$ & $250+$ \\
\hline \hline
\end{tabular}

PRPER collaborations happen via partnerships at multiple institutions than for either PERC or FIE. Thus inter-institutional networks are used more often for completing PRPER work while intra-institution collaborations are used more often for publication productivity in PERC and FIE.

After institutional data names were collected and cleaned to align identical institutions that were named differently, there were 356 different institutions that were given as affiliations for PRPER authors. In total there were 1,144 recorded instances of institutions participating in the 606 papers. (Institutions were recorded once on each paper regardless of the number of authors who were affiliated with that institution, and each author was allowed only one affiliation. If an author listed multiple affiliations, an affiliation not already used on that paper was recorded where possible.) Table IV lists the top 20 institutions who participated in PRPER in descending order of the number of papers. Table IV also gives the overall percentage of PRPER papers that this count represents, and contrast this to the PERC data for these institutions.

Both PRPER and PERC had very similar institutions that contributed with University of Colorado Boulder and University of Pittsburgh being the most common affiliation. Some notable differences were: Texas State University was listed on 31 PERC papers but only 3 PRPER; University of Central Florida was given as an affiliation for 28 PERC papers but only 8 PRPER papers; KU Leuven was one of the top PRPER affiliations with 12, but only 1 PERC paper; University of Zagreb and West Virginia University each had 11 PRPER papers but 0 and 3 PERC papers respectively.

It is notable that for both PRPER and PERC these 20 institutions account for a majority of papers published $(58 \%$ and $56 \%$, respectively). FIE on the other has a significantly broader community where the top 20 institutions account for only $25 \%$ of papers, and only three institutions are on both top 20 lists. These are Ohio State, University of Illinois, and Rochester Institute of Tech. [2]. This is notable because it suggests that students at other types of institutions may not be well represented in PER research [15]. Also, this suggests that there may be inter-institutional barriers to research collaboration between engineering and physics education.

In addition to the diversity of institutional collaborations in PRPER, 37\% of papers gave author affiliations from 2 or more countries. However, 450 (74\%) of papers listed the U.S. for at least one author. In total there were 40 different countries that participated in PRPER authorship. Listed in order by number of papers for all countries with 10 or more papers, these countries were: USA (450 papers); Canada (25 papers); China (18); United Kingdom (18); Croatia (14); Israel (14); Finland (13); Belgium (12); Germany (12); Ireland (11); Italy (11); Norway (11); and Sweden (11).

\section{CONCLUSIONS}

A text-based analysis of all PRPER papers between 2010 and 2019 was completed to identify funding sources and patterns of author collaboration, and these results were compared to PERC and FIE proceedings to contextualize the findings.

It was observed that, the PER community reports funding on an average of $70 \%$ of the papers published in PRPER and PERC. This is more than double the funding percentage reported for FIE. However, the funding to the PER community is more homogeneous than the funding to FIE with $67 \%$ of funding coming from NSF and on average $79 \%$ of this coming from the EHR directorate. Diversifying these funding streams to the PER community could be useful in maintaining this high instance of funding as the community grows.

In addition, these data show that PRPER has a diverse community across the U.S. and abroad. There were over 300 unique institutions from 40 different countries with over 900 authors participating in authorship of PRPER articles from 2010 to 2019. Also, PRPER papers are unique in comparison to both FIE and PERC proceedings in the amount of interinstitutional collaboration of authorship with $54 \%$ of publication having authors at more than one institution and $25 \%$ at more than three places. However, it should be noted that much of the PRPER authorship, 58\% of papers, have at least one author from the 20 institutions listed in Table IV that are large universities with Physics Education Research groups. This suggests these places may be key to publication productivity and research in PER. 
[1] R. Rosenblatt, "Investigating partnerships and funding for the Physics Education Research community," Paper presented at the Physics Education Research Conference 2020, Virtual Conference, July 22-23, 2020.

[2] R. Rosnblatt, "Investigating co-authorship, research themes, and funding streams for the Frontiers in Education community,", Paper presented at at the Frontiers in Education Conference 2021, October 11-14, 2021.

[3] Sustainable Development Goals. Retrieved from https://sustainabledevelopment.un.org/ [May 1, 2021]

[4] J. Roschelle, W. Martin, J. Ahn, and P. Schank, "Cyberlearning Community Report: The State of Cyberlearning and the Future of Learning With Technology," Menlo Park CA: SRI International, 2017. https://circlcenter.org/resources/communityreport/

[5] B. K. Jesiek, M. Borrego, and K. Beddoes, "Advancing global capacity for engineering education research: relating research to practice, policy and industry," European Journal of Engineering Education, 35(2), 117-124, 2010. https://doi.org/10.1080/03043791003596928

[6] J. Lucena, G. Downey, B. Jesiek, and S. Elber, "Competencies beyond countries: the re-organization of engineering education in the United Sates, Europe, and Latin America," Journal of Engineering Education, 97 (4), 433-447, 2008. https://doi.org/10.1002/J.2168-9830.2008.TB00991.X

[7] https://journals.aps.org/prper/

[8] https://www.per-central.org/perc/Proceedings.cfm

[9] http://fie2014.fie-conference.org/
[10] P. C. Wankat, "Analysis of the first ten years of the Journal of Engineering Education," Journal of Engineering Education, 93(1), 13-21, 2004. https://doi.org/10.1002/j.21689830.2004.tb00784.x

[11] T. O.B. Odden, A. Marin, and M. D. Caballero, "Thematic analysis of 18 years of physics education research conference proceedings using natural language processing," Physics Review Physics Education Research, 16 (1), 2020. https://dio.org/10.1103/PhysRevPhysEducRes.16.010142

[12] L. Malmi, T. Adawi, R. Curmi, E. de Graaff, G. Duffy, C. Kautz, P. Kinnuen, and B. Williams, "How authors did it - a methodological analysis of recent engineering education research papers in the European Journal of Engineering Education," European Journal of Engineering Education, 43 (2), 171-189, 2018. https://doi.org/10.1080/03043797.2016.1202905

[13] A. Pawley, C. Schimpf, and L. Nelson, "Gender in Engineering Education Research: A content Analysis of Research in JEE, 1998-2012," Journal of Engineering Education, 105 (3), 508528, 2016. https://doi.org/10.1002/jee.20128

[14] K. A. Anderson, M. Crespi, and E. C. Sayre, "Linking behavior in the physics education research coauthorship network," Physical Review Physics Education Research 13, 010121 (2017). DOI:10.1103/PhysRevPhysEducRes.13.010121

[15] S. Kanim and X. Cid, "Demographics of physics education research," Physical Review Physics Education Research, 16(2), $020106 \quad$ (2020). DOI:10.1103/PhysRevPhysEducRes.16.020106

[16] NSF Public Award Search https://www.nsf.gov/awardsearch/ 